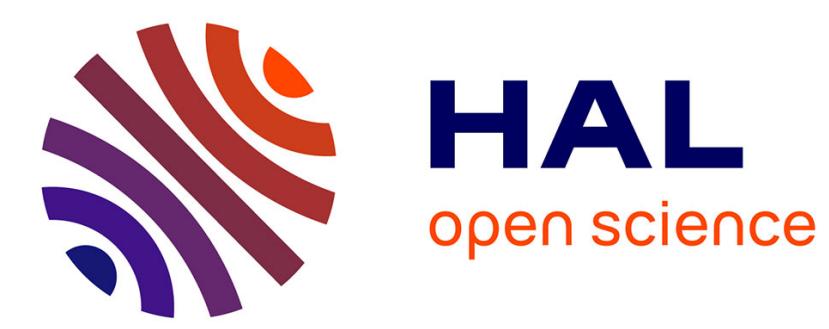

\title{
Vortex patterns generated by a heaving flexible plate
}

Florine Paraz, Christophe Eloy, Lionel Schouveiler

\section{To cite this version:}

Florine Paraz, Christophe Eloy, Lionel Schouveiler. Vortex patterns generated by a heaving flexible plate. Journal of Flow Visualization and Image Processing, 2014, 17 (4), pp.295 - 297. 10.1007/s12650014-0208-3 . hal-01089407

\section{HAL Id: hal-01089407 https://hal.science/hal-01089407}

Submitted on 12 Dec 2014

HAL is a multi-disciplinary open access archive for the deposit and dissemination of scientific research documents, whether they are published or not. The documents may come from teaching and research institutions in France or abroad, or from public or private research centers.
L'archive ouverte pluridisciplinaire HAL, est destinée au dépôt et à la diffusion de documents scientifiques de niveau recherche, publiés ou non, émanant des établissements d'enseignement et de recherche français ou étrangers, des laboratoires publics ou privés. 


\title{
Vortex patterns generated by a heaving flexible plate
}

\author{
F. Paraz · C. Eloy · L. Schouveiler
}

Received: date / Accepted: date

\begin{abstract}
We present dye visualizations of the wake behind a flexible plate flow when its leading edge is forced into harmonic heave motion. We show that, when the forcing amplitude is sufficiently large, a reverse Bénard-von Kármán vortex street is formed in the wake, indicative of the production of positive thrust.
\end{abstract}

Keywords Flexible plate Flapping plate Vortical structures $\cdot$ Thrust

\section{Introduction}

Flapping fins are commonly used by swimming animals to produce locomotive forces. These fins have inspired a vast amount of studies motivated, for a large part, by the design of novel propulsion devices. These studies have generally considered a foil or a plate harmonically actuated in heave motion (translation), in pitch motion (rotation), or in a combination of both motions. Interestingly, the propulsive performances have been shown to increase when a flexible plate, rather than a rigid one, is used. The thrust produced by flapping fins is an increasing function of the amplitude of the trailing edge deflection [1]. To assess the propulsive performances of such systems, the knowledge of the deformation kinematics is thus of primary importance.

In the present work, we consider the flow generated by a flexible plate whose leading edge is forced into harmonic heave motion. It follows a previous study in which we have investigated the plate response to this forcing [2]. In particular, we have evidenced that the deflection amplitude of the trailing edge was maximal when the forcing frequency was resonant with a structural eigenfrequency of the flexible plate. We now turn to the visualization of the vortical structures generated in the wake of this model swimmer, as it is known to be a good indicator of the thrust produced [3].

F. Paraz · C. Eloy · L. Schouveiler

Aix Marseille Université, CNRS, Centrale Marseille, IRPHE UMR 7342, 13384 Marseille, France

E-mail: florine.paraz@irphe.univ-mrs.fr 


\section{Experimental setup}

The experimental setup, shown in Fig. 1a, consists of a horizontal flexible plate, of bending rigidity $B$, immersed in a uniform horizontal flow of velocity $U$ generated by free-surface water channel. The plate is of thickness $e=0.004 \mathrm{~m}$, span $s=$ $0.12 \mathrm{~m}$, and chord $c=0.12 \mathrm{~m}$. It is molded out of polysiloxane with a tapered trailing edge and with a rigid axis inserted at the rounded leading edge. This rigid axis is attached to a U-frame that can be actuated with a linear motor into harmonic motion such that the leading elevation is imposed: $A_{L E} \cos (2 \pi f t)$. The flow around the plate is confined between two vertical parallel walls to avoid the perturbations due to the U-frame.

The explored ranges of the experimental parameters $A_{L E}, f, B$ and $U$ are given in Fig. 1b. To visualize the vortical structures generated by the plate motion, the plate is coated with a solution of fluorescent dye prior immersion. The patterns created by the dye entrained in the flow are illuminated at mid-span with a vertical sheet of light generated with an Argon Ion laser. Images are captured, through the transparent channel sidewall, with a camera aligned perpendicular to the light sheet.

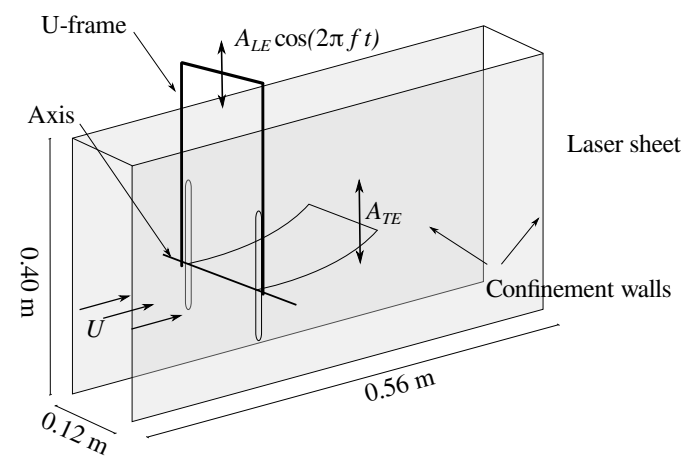

(a)

\begin{tabular}{lc}
\hline$A_{L E}(\mathrm{~m})$ & $0.004-0.014$ \\
$f(\mathrm{~Hz})$ & $0.2-6$ \\
$B(\mathrm{Nm})$ & $0.018-0.053$ \\
$U\left(\mathrm{~m} . \mathrm{s}^{-1}\right)$ & $0-0.1$ \\
\hline
\end{tabular}

(b)

Fig. 1 (a) Sketch of the experimental setup and (b) ranges of the experimental parameters explored.

\section{Results and perspectives}

In Fig. 2, the evolution of the vortex patterns in the wake of the heaving flexible plate are visualized with dye over one period. The experimental parameters are $A_{L E}=0.004 \mathrm{~m}, f=0.8 \mathrm{~Hz}$ and $U=0.05 \mathrm{~m} \mathrm{~s}^{-1}$, corresponding to a resonant case (i.e. a maximum of the trailing edge deflection amplitude).

In Fig. 2, it can be observed that a vortex forms at the leading edge on the upper side during the plate downstroke (Figs 2a-c) and a second one on the lower side during the upstroke (Figs $2 \mathrm{~d}-\mathrm{f}$ ). These vortices are likely due to a flow separation at the leading edge. This separation occurs because the combination of the incoming flow and of the heave motion results in a non-zero effective angle of attack at the 


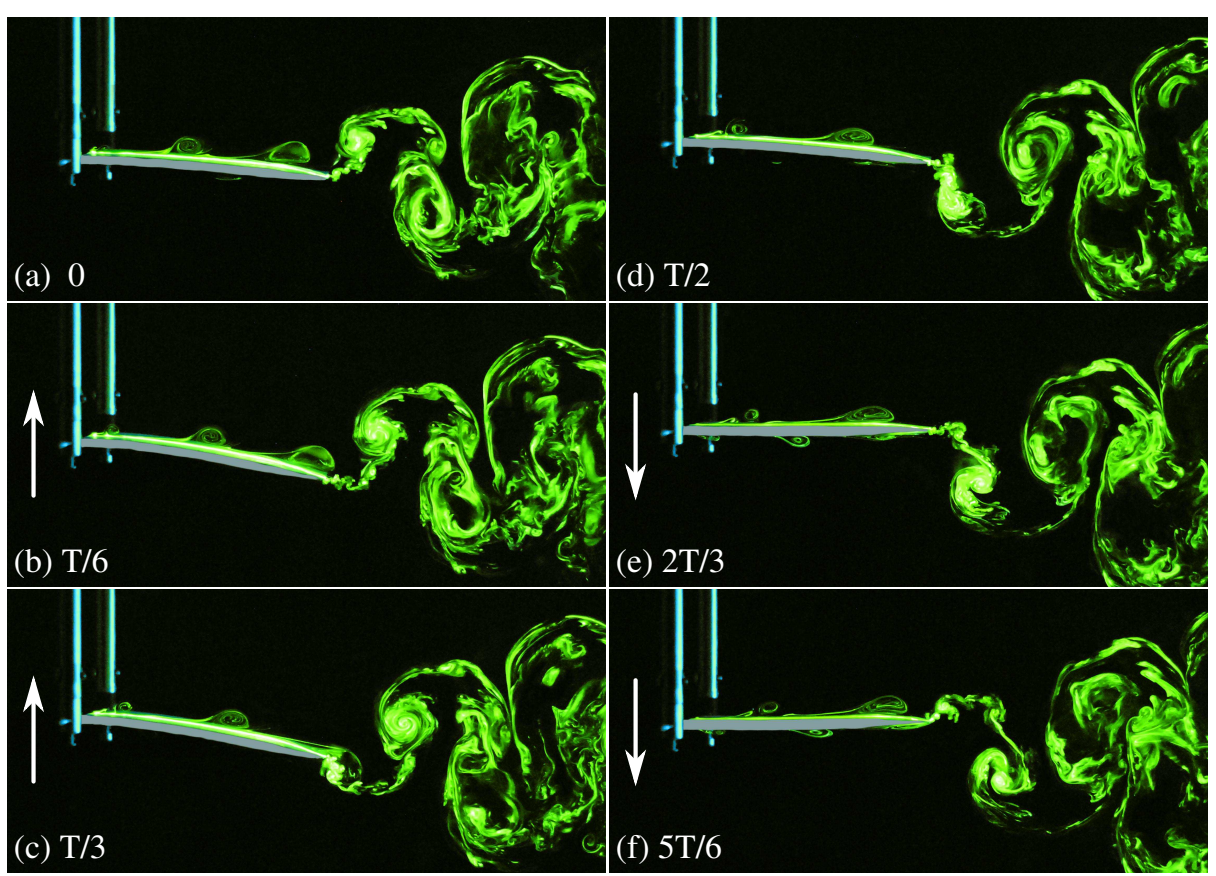

Fig. 2 Dye visualizations of the vortices generated by the heaving flexible plate over one period for $A_{L E}=0.004 \mathrm{~m}, f=0.8 \mathrm{~Hz}$ (period $T=1.25 \mathrm{~s}$ ), $B=0.018 \mathrm{Nm}$ and $U=0.05$ $\mathrm{m} . \mathrm{s}^{-1}$ (flow from left to right). The motion of the plate leading edge is indicated by an arrow.

leading edge. For the parameters used here, this angle is $\arctan \left(2 \pi f A_{L E} / U\right)=$ $23^{\circ}$. The leading edge vortices can be followed on the image sequence as they travel along the plate chord up to the trailing edge where additional vortices are generated. Both vortices combine into large scale vortices shed twice per cycle: the shedding of a counter-clockwise vortex is seen in Fig. 2a and of a clockwise one in Fig. 2d. As they are advected downstream, they form a reverse Bénard-von Kármán vortex street, similar to the wakes observed behind bluff bodies but with reversed sense of rotation of the vortices. This reverse Bénard-von Kármán wake corresponds to a jet-like average velocity profile and is thus associated with thrust production. We are currently trying to measure this thrust directly to confirm quantitatively the present results of qualitative nature.

Acknowledgements We warmly thank Thomas Leweke for his help with the visualizations.

\section{References}

1. Lighthill, M. J., Note on the swimming of slender fish, J. Fluid Mech, vol. 9, pp. 305-317 (1960).

2. Paraz F., Eloy C., Schouveiler L., Experimental study of the response of a flexible plate to a harmonic forcing in a flow, C. R. Mécanique, in press (2014).

3. Dabiri, J.O., On the estimation of swimming and flying forces from wake measurements, J. Exp. Biol. 208, 3519-3532 (2005). 